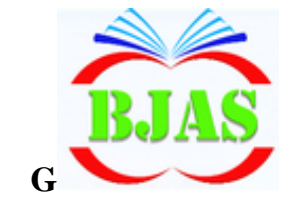

ISSN $1814-5868$
Available online at http://bajas.edu.iq

https://doi.org/10.37077/25200860.2019.195

College of Agriculture, University of Basrah

Basrah J. Agric. Sci., 32(1): 88-98, 2019
Basrah Journal

of Agricultural

Sciences

E-ISSN: 2520-0860

\title{
The Application of Manure (Poultry Wastes) and Bio-Formulations of Trichoderma harzianum and $T$. viride and Their Interaction to Control Root-knot Disease on Radish and Chard
}

\author{
Nuha A. Al-Zehebawi, Dhia S. Al-Waily \& Labeed A. Al-Saad* \\ Department of Plant Protection, College of Agriculture, University of Basrah, Iraq \\ *Corresponding author E-mail: la_alsaad@yahoo.com \\ Received 1 April 2019; Accepted 2 June 2019; Available online 12 June 2019
}

\begin{abstract}
The study was designed to examine the effect of manure (poultry wastes) and bio-formulations of Trichoderma harzianum and $T$. viride separately or with some, to control root-knot disease on radish (Raphanus sativus L.) and chard (Beta vulagaris var.cicla (L.)). The study included the isolation of pathogenic nematode of both plant roots, morphological and molecular identification, examination of the pathogenicity in vitro and in vivo and green house experiments involved application of manure and fungal bio-formulations treatments. The morphological and molecular identification confirmed the identity of root-knot nematode, as Meloidogyne javanica, which was pathogenic to radish and chard. The recorded infection severity was 89 and $95 \%$ respectively. The green house experiment results revealed that MThTv treatment was significantly reduced infection severity to $0 \%$ for radish and chard in contaminated soil (CS) compared with control positive treatment (55.17 and 40\%) respectively. MThTv treatment also showed a highest plant height for Radish in non-nematode-contaminated soil (NCS) and CS treatment $(17.85$ and $16.50 \mathrm{~cm})$ respectively compared with control positive treatment $(5.00 \mathrm{~cm})$, while the highest plant height of Chard was $24.5 \mathrm{~cm}$ in MThTv-NCS. The wet weight index in Radish showed a superiority of MThTv and MTh in NC on other treatments (201.75 and 189.5 g.plant $\left.{ }^{-1}\right)$ respectively followed by MThTv-NCS treatment (184.5 g.plant ${ }^{-1}$ ) compared with 19.25 gm.plant $^{-1}$ in control treatment. In Chard the results showed similar pattern represented by superiority of MThTv-NC treatment (255.25 gm.plant ${ }^{-1}$ ) followed by MThTv-NCS (190.75 gm.plant ${ }^{-}$ $\left.{ }^{1}\right)$ compared with $37.50 \mathrm{gm} /$ plant for positive control.
\end{abstract}

Keywords: Nematode, Meloidogyne javanica, Biological control, radish, Chard, Trichoderma.

\section{Introduction}

Meloidogyne spp. are important plant parasitic nematodes affecting wide host range that is close to 2500 hosts. Root-knot disease is one of the most prevalent diseases in the world that causes major losses in field crops, vegetable crops, ornamental plants and weeds, which is include Cucumbers, lettuce, papaya, onions, peaches, peppers, potatoes, soybeans, spinach, zucchini, sugarcane, sugar beets, tobacco, wheat, and hyssop, as well as radish and chard plants (Bird \& Kaloshian, 2003; Davis et al., 2004). 
The radish (Raphanus sativus L.) is an edible root vegetable plant belongs to the Brassicaceae family that was originated in Asia and domesticated by Greeks and Egyptians in the ancient eras. Each $100 \mathrm{~g}$ of roots contains $94 \%$ water, 20 calories, $1 \mathrm{~g}$ of protein, $4 \mathrm{~g}$ of carbohydrate, $37 \mathrm{mg}$ of calcium, $31 \mathrm{mg}$ phosphorus, 30 universal unit of vitamin $\mathrm{A}$ and $24 \mathrm{mg}$ of vitamin $\mathrm{C}$ in addition to mustard oil (Matloob et al., 1989).

The chard (Beta vulagaris var.cicla) is a leafy green vegetable of the Chenopodiaceae family. The Canary Islands and the Mediterranean Sea are origin lands of this plant (Matloob et al., 1989).

The radish and chart plant mostly infected with several root diseases including root-knot disease, which is recognized by forming of root-knots on the plant root system that affecting the functional efficiency of the root, which reflected as a malfunction in absorption of the water and nutrients. As a result, wilt symptoms will appear in hot weather and regain their status in the early morning (Abad et al., 2003).

For long decades, nematocides like Mocap, Fouradan, Vydate, and Nemacor were used to control root-knot nematodes, which is companied with serious adverse effects to the environment in general and to the human and animal health in particular. Alternatively, biological control considered as a best environmentally friendly solution to replace chemical control. Among several biocontrol agents, the fungi, Trichoderma viride and $T$. harzianum were successfully employed in the control of root-knot nematodes (Mukerji \& Garg, 1987; Agrios, 2005).

Regarding the importance of this disease and the lack of studies about it Iraq, in addition to the large losses caused by, this study aimed to investigate the prevalence of this disease and the possibility of control it biologically.

\section{Materials \& Methods}

\section{Samples collection and preparation}

The radish and chard infected root samples were collected from several location of Basrah province included Al-Hotta and AlHartha. The samples prepared according to McClure et al. (1972) that involved clean up the collected roots with tap water to remove soil debris. The roots were cut in to small pieces (about $2 \mathrm{~cm}$ ) then washed with tap water through 60 mesh sieve then transferred to the blender contained $100 \mathrm{ml}$ of tap water and $500 \mathrm{ml}$ of $0.1 \%$ sodium hypochlorite $(6 \%$ of commercial formulation), the content mixed for $40 \mathrm{~s}$ at high speed. The mixture passed through several sieves $(100,400$ and 500 mesh) respectively, the samples were collected with $40 \mathrm{ml}$ of tap water in $50 \mathrm{ml}$ test tubes then centrifuged at $1000 \mathrm{rpm}$ for 40s. The supernatant (contains eggs) poured in 400 mesh sieve and washed 3 times with $100 \mathrm{ml}$ of distilled water and the eggs were collected with distilled water in $205 \mathrm{ml}$ conical flask.

\section{Morphological identification}

The collected eggs from the past step were incubated for 3-5 days on $28^{\circ} \mathrm{C}$ (McClure et $a l .$, 1972). The specimen were identified morphologically by second author according to Hirschmann (1985), Luc et al. (1990) and Perry et al. (2010).

\section{Molecular identification}

The collected eggs suspension $(10 \mathrm{ml})$ was centrifuged at $1000 \mathrm{rpm}$ for $15 \mathrm{~min}$. The supernatant was discarded and the pellet was transferred to a mortar and grinded with liquid nitrogen to a fine powder. About $20 \mathrm{mg}$ of 
powder was transferred to $1.5 \mathrm{ml}$ Eppendorf tube for Genomic DNA extraction.

The DNA was isolated using Genomic DNA Purification kit A1120 (Promega, USA) according to the manufacturer instractions.

The PCR reaction was performed according to Aydinli \& Mannen (2016) using Sequencecharacterized amplified region (SCAR) primers for Fjav: GGTGCGCGATTGAACTGAGC and Rjva: CAGGCCCTTCAGTGG-AACTATAC. The reaction conditions mixture contained $25 \mu \mathrm{l}$ of Taq DNA Master Mix RED (Amplicon, Denmark), $2.5 \mu$ l of each primer, $100 \mathrm{ng}$ of DNA templet and the mixture completed to $50 \mu \mathrm{l}$ with DD-Water. The amplification was performed using MyGenieTM 96/384 thermal Block (BioNEER, Inc, Korea), the reaction conditions involved initiation on $94^{\circ} \mathrm{C}$ for $3 \mathrm{~min}$ followed by 35 cycles included denaturation on $94^{\circ} \mathrm{C}$ for $30 \mathrm{~s}$, annealing on $60^{\circ} \mathrm{C}$ for $30 \mathrm{~s}$ and extension on $72^{\circ} \mathrm{C}$ for $1 \mathrm{~min}$ followed by $7 \mathrm{~min}$ of final extension on $72^{\circ} \mathrm{C}$.

The quantity and quality of DNA were confirmed by Nano drop device (TermoScientificTM, NanoDrop 2000, USA) at wavelength 260/280. The samples were send to Macrogen Co. (Korea) to confirm PCR product.

\section{Examining the pathogenicity of M. javanica}

Radish and chard seeds were used to examine the pathogenicity of M.javanica. The experiment involved preparing a mixture of sand soil: compost $(3: 1)$, the mixture was decontaminated with formaldehyde $(20 \mathrm{ml} / \mathrm{L}$ of water for each $12.5 \mathrm{~kg}$ of mixture), the mixture packed in plastic pots (500 gm), the treatments (M.javanica contaminated soil "NC" and non-contaminated soil "NCS") were considered in triplicates. The seeds were planted in the pots ( 5 seeds/pot) and irrigated carefully. After 1 week, 1000 second stage juvenile were used to inoculate each pot and the infection percentage was calculated after 3 months of inoculation (Singh \& Siddiqui, 2012).

\section{Fungal isolates}

T. harzianum and $T$. viride isolates were got as a gift from second author. The fungi were activated on $9 \mathrm{~cm}$ Petri plates containing PDA medium at $27^{\circ} \mathrm{C}$ for 4 days then stored on PDA slants for future use (Alwaely, 2014). The both isolates were used in all next experiment of this study.

\section{Formulation of biological control agents $T$. harzianum and $T$. viride}

The both fungal isolates were re-activated on PDA for 4 days at $27^{\circ} \mathrm{C}$. Using cork poorer, a $0.5 \mathrm{~cm}$ mycelium disks were used to inoculate $500 \mathrm{ml}$ conical flasks containing $200 \mathrm{gm}$ of $1 \mathrm{~h}$ autoclaved mixture of Wheat bran: Sand: water $(2: 1: 1) \mathrm{W} / \mathrm{W} / \mathrm{V}$ then incubated at $30^{\circ} \mathrm{C}$ for 15 days with shaking in interval of 2 days (Papavizas et al., 1982).

\section{Field experiment}

The field experiment was carried out at the research station of the College of Agriculture, University of Basrah, Garmat Ali campus on $22 / 2 / 2018$. The dimensions of the experiment plot was $16 \times 4 \mathrm{~m}^{2}$, the soil was plowed and divided in to three $16 \times 0.5 \mathrm{~m}$ sub-plots with a distance of $50 \mathrm{~cm}$ among sub-plots. The subplots were divided in to separate experimental units $(1 \times 0.5 \mathrm{~m})$. The organic fertilizer (fermented poultry wastes) was added by mixing with soil followed by addition of biocontrol formulation $\left(10 \mathrm{~g} . \mathrm{m}^{-1}\right)$ (Al-Waily, 2004) to the particular treatments in triplicates (table 1). After three days the seeds were planted in pits with a distance of $40 \mathrm{~cm}$ among them then drip irrigated. A couple of weeks later, they inoculated with M. javanica (1000 
Al-Zehebawi et al. / Basrah J. Agric. Sci., 32 (1): 88-98, 2019

eggs and/or second stage juvenile/plant: $2 \mathrm{~cm}$ from plant and $3 \mathrm{~cm}$ in depth) (Singh \& Siddiqui, 2012). The considered parameters of this experiment were infection percentage, plant high and wet weight of the plant.

Table (1): The experimental design of field experiment.

\begin{tabular}{cl}
\hline Treatment & \multicolumn{1}{c}{ Details } \\
\hline ThTvM & T. harzianum + T. viride + Manor \\
\hline TvM & T. viride+ Manor \\
\hline ThM & T. harzianum + Manor \\
\hline $\mathrm{M}$ & Manor \\
\hline ThTv & T. harzianum + T. viride \\
\hline $\mathrm{Tv}$ & T. viride \\
\hline $\mathrm{Th}$ & $T$. harzianum \\
\hline $\mathrm{Mj}$ & Positive control (The soil inoculated with $M$. javanica) \\
\hline
\end{tabular}

All treatments were applied in non $M$. javanica inoculated experimental units.

\section{Estimation of root-knot infection severity on radish}

The infection severity of M.javanica on radish was estimated using the root-not disease

\section{Infection severity \%}

$$
=\frac{\sum(\text { No. of non infected plants } \times 0+\cdots+\text { No. of dead plants } \times 5)}{\text { No. of plants } \times \text { highest degree }} \times 100
$$

\section{Estimation of root-knot infection severity on chard}

The Bridge \& Page (1980) disease index of root-nots was used to estimate the infection severity. The index involved six degrees scale (No notes $=0$; little No. of notes hard to see $=$ 1 ; some of big notes but not in main roots $=2$; $50 \%$ of root were infected, notes on main roots and shrinkage of root system $=3$; notes observed on most main roots $=4$; All roots are infected $=5$ ). Mickenny (1923) formula was used to calculate the infection percentage. index (designed in this study) that involved a five degrees scale (No infection= 0; 1-10 nots $=1 ; 11-20$ nots $=2 ; 21-30$ notes $=3 ; 31-40$ notes $=4$; more than $41=5$ ).

The infection severity calculated according to Mckinney (1923) formula that reported in Al-Waily (2004):

\section{Results \& Discussion}

\section{The morphological and molecular identification}

The morphological identification results (Fig. 1) revealed that all isolated nematodes were returned to the species $M$. javanica according to the diagnostic traits (length and diameter were about: $395 \times 130 \mu \mathrm{m}$ for $\mathrm{J} 2 ; 1400 \times 30$ $\mu \mathrm{m}$ for male; $700 \times 380 \mu \mathrm{m}$ for female) in Hirschmann (1985), Luc et al. (1990) and Perry et al. (2010). 
Al-Zehebawi et al. / Basrah J. Agric. Sci., 32 (1): 88-98, 2019

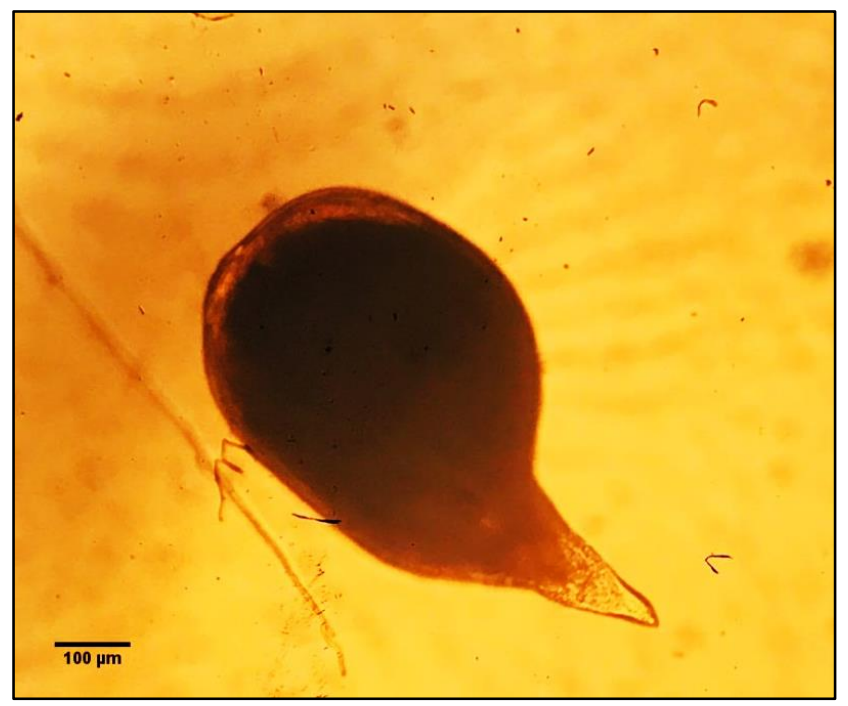

Fig. (1): M. javanica female, the microscope magnification is $40 \mathrm{X}$.

The morphological identification of all isolates was confirmed molecularly by the electrophoresis results of a high specific PCR amplification of unique $670 \mathrm{bp}$ segment (Fig. 2). The mentioned molecular method considered as a fast and accurate method usually used to identify $M$. javanica as the
SCAR primers were high specific and mostly produces a PCR product only for $M$. javanica despite of the growth stage and sample purity (the samples my contains environmental DNA contamination from host plant and/or other associated species that can affect the identification accuracy) that is leads to apply easy and fast identification process (Zijlstra $e t$ al., 2000; Aydinli \& Mennan, 2016).

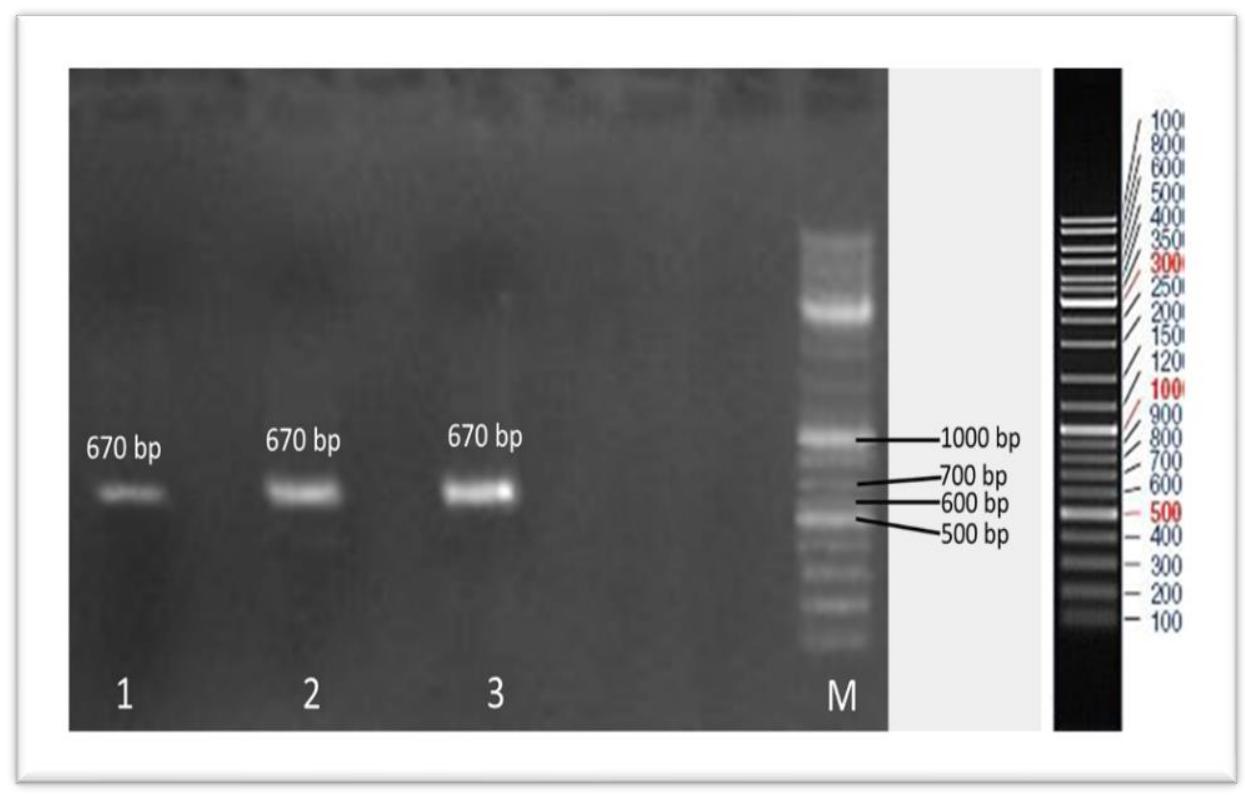

Fig. (2): Electrophoresis of three $M$. javanica PCR product using Fjav and Rjav SCAR primers. Lan 1 and 2 represent $M$. javanica that isolated from radish roots; Lan 3 represent $M$. javanica isolated from chard roots and $M$ is the standard Ladder. 


\section{The pathogenicity of M.javanica}

M. javanica pathogenicity tests (Fig. 3) were confirmed their ability to infect $89 \%$ of examined radish and $95 \%$ of chard plants effectively with no significant differences between them $(\mathrm{P}=0.157)$, while no infection signs were observed on non-inoculated (control-) radish and chard plants.

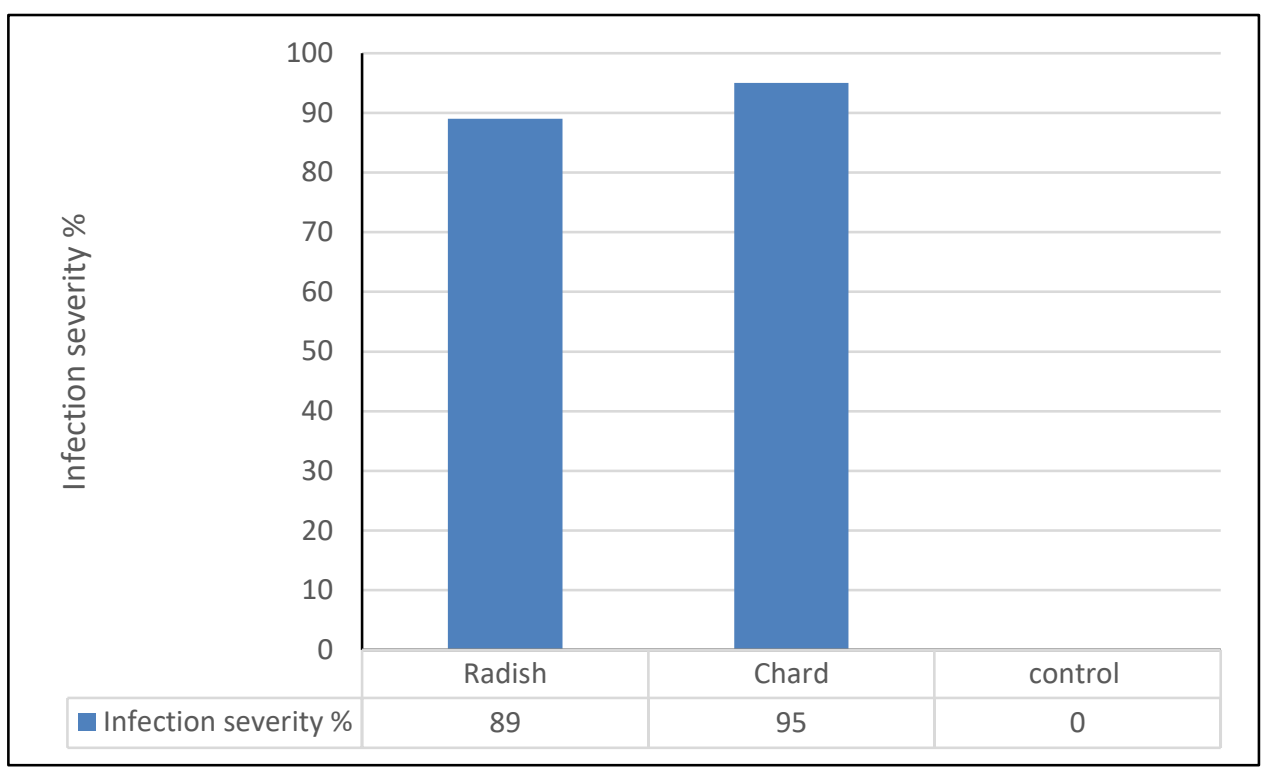

Fig. (3): The pathogenicity of $M$. javanica isolates on radish and chard plants.

\section{Infection severity}

The infection severity was varied relative to the host plant and the applied treatment (Fig. 4). On radish, no infection was observed when the plant treated with MThTv treatment which significantly surpass all other treatments followed by $\mathrm{TvTh}$ treatment (4.30\%), while $\mathrm{M}$ treatment showed the lowest suppression effect $(31.67 \%)$ that was significantly excel the control treatment (55.17\%). On Chard, the same infection severity pattern was observed that represented by superiority of MThTv treatment $(0 \%)$ followed by MTv and MTh (2.67, 5.33\%) respectively and the lowest inhibition effect was recorded in M treatment. Anyhow, all the applied treatments were exceeded the control treatment $(40.00 \%)$ significantly.

The results above revealed that any treatment involved Trichoderma spp. Showed effective reduction in infection severity. Trichoderma spp. is well known effective biocontrol agent having several antagonistic mechanisms against nematodes includes the ability to surpass hatching of nematode eggs and preventing their development to the second stage juvenile that reduces the first inoculum density in soil, which in turn leads to reduce the infection development chances (Cook, 2000). Additionally, the pathogenicity, competition, and host systemic resistance induction can considered as helpful factors to prevent and/or reduce the infection severity (Baker, 1989; Okoth et al., 2011). 
Al-Zehebawi et al. / Basrah J. Agric. Sci., 32 (1): 88-98, 2019

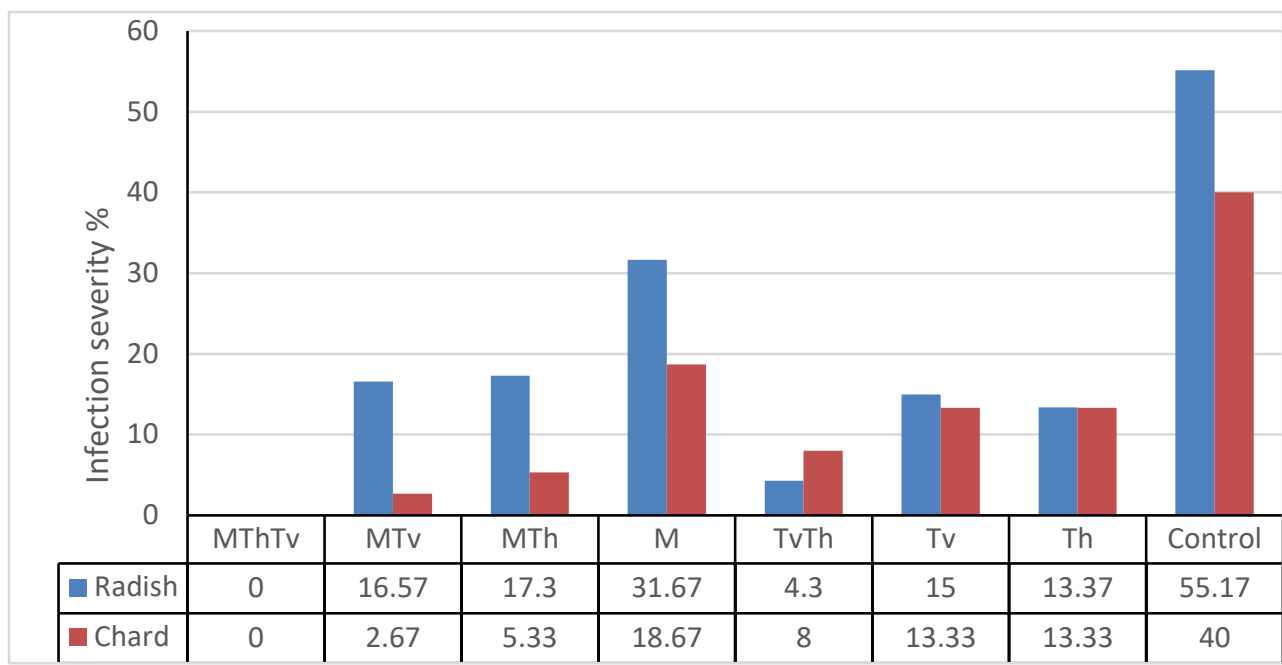

Fig. (4): The assessment of infection severity under different experimental treatments. Each mean represents 4 replicates.

\section{Field experiment}

\section{Plant height}

The radish plant height was significantly affected by the applied treatments (Fig. 5). The results showed significant differences among factors and/or factorial treatments represented by superiority of MThTv treatment on all other treatments significantly in both CS and NCS treatments (16.50, 17.25 $\mathrm{cm}$ ) respectively while the lowest height means were observed in $\mathrm{M}$ treatments (9.00,
$9.25 \mathrm{~cm}$ ) respectively, which were significantly exceeded the control treatment $(5.00 \mathrm{~cm})$ in $\mathrm{CS}$ treatment, while significant decrease was recorded in NCS treatment comparing with control $(11.50 \mathrm{~cm})$. A significant increase in plant height was recorded in all biocontrol agent included treatments in both CS and NCS treatments comparing with control treatments separately.

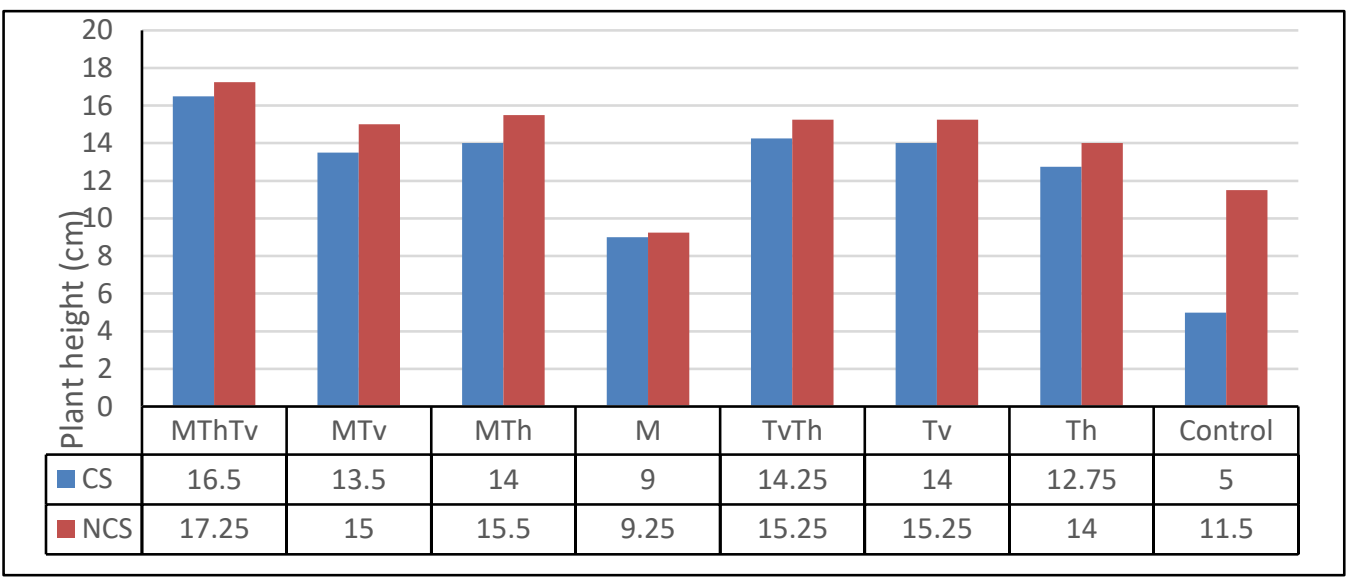

Fig. (5): The effect of experimental treatments on radish height in both $M$. javanica contaminated and non-contaminated soils. Each mean represents 4 replicates. LSD 0.05 of interaction $=0.27, \mathrm{LSD} 0.05$ of Soil $=0.38$. 
The chard height was also influenced significantly by field experiment treatments (Fig. 6). The results demonstrated that MThTv excel all other treatments in both Cs and NCS $(17.25,24.25 \mathrm{~cm})$ respectively with a significant difference between them. The lowest height means were also recorded in $\mathrm{M}$ treatments $(13.75,16.50 \mathrm{~cm})$ in contaminated and nematode free soils respectively with significant differences between them. The positive controls $(14.88,19.19 \mathrm{~cm})$ respectively showed significantly lower means then all other treatments.

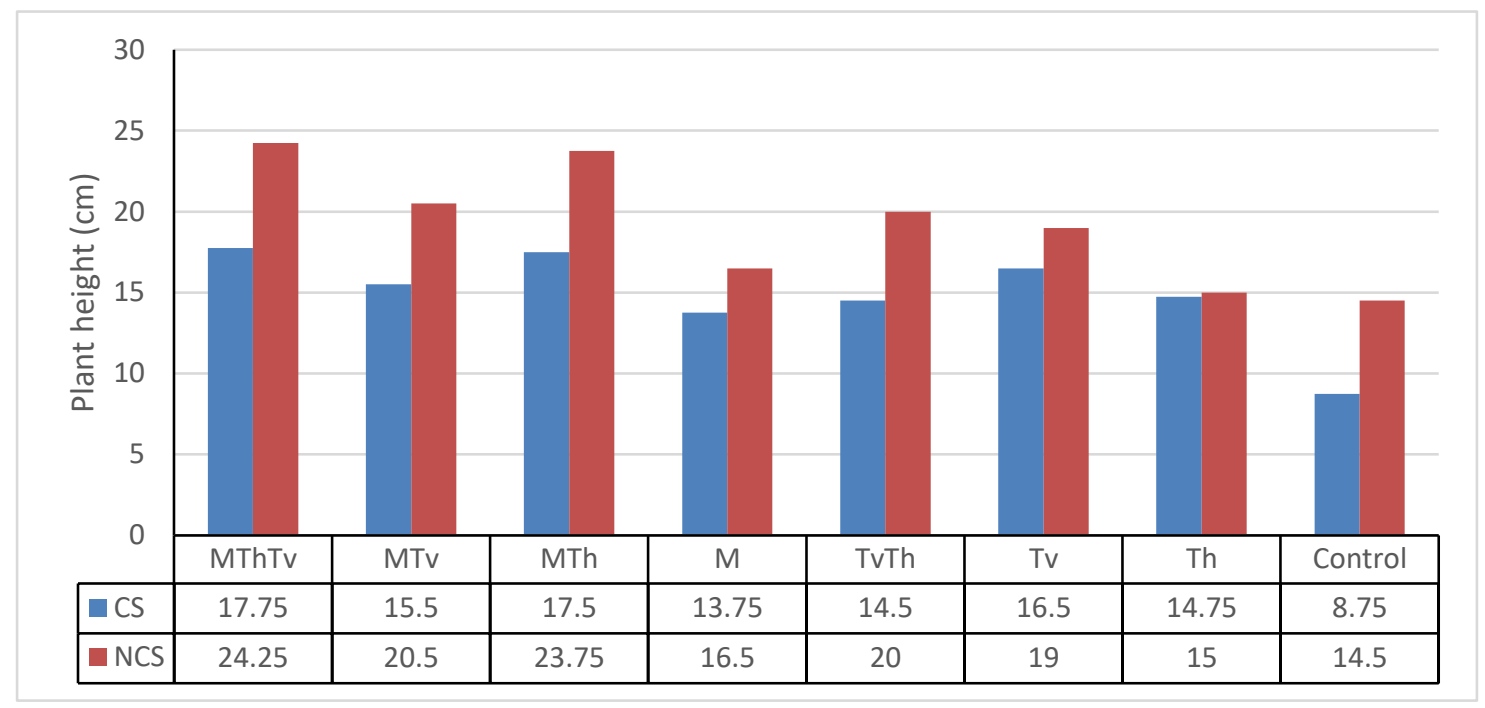

Fig. (6): The effect of experimental treatments on chard height in both M.javanica contaminated and non-contaminated soils.Each mean represents 4 replicates. LSD 0.05 of interaction $=0.41$, LSD 0.05 of Soil $=0.59$.

\section{The plant weight}

The means of vegetative wet weight showed a similar pattern to the height results (Fig. 7). All the treatments were significantly exceeded the control treatments in both Cs and NCS treatments. The highest wet weight was recorded in MThTv treatments (184.5 and $201.75 \mathrm{~g})$ respectively, where the lowest wet weight observed in $M$ treatments (39.25 and 83 g) respectively comparing with control treatments (19.25 and 36.25) respectively. Totally, the nematode infection caused a significant reduction in plant wet weight $(98.5$ g) comparing with control (128.56 g).
The chard wet weight means (Fig. 8) arranged ascendingly from $\mathrm{M}$ treatments (63.25, $73.75 \mathrm{gm})$ for CS and NCS treatments respectively to the highest wet weight in MThTv treatments (190.75 and $255.25 \mathrm{gm}$ ) respectively with significant differences among CS and NCS treatments separately. A significant differences were also observed between CS and NCS either totally (14.88 and $19.19 \mathrm{gm})$ respectively and separately. All the treatments were exceeded the control treatments significantly. 
Al-Zehebawi et al. / Basrah J. Agric. Sci., 32 (1): 88-98, 2019

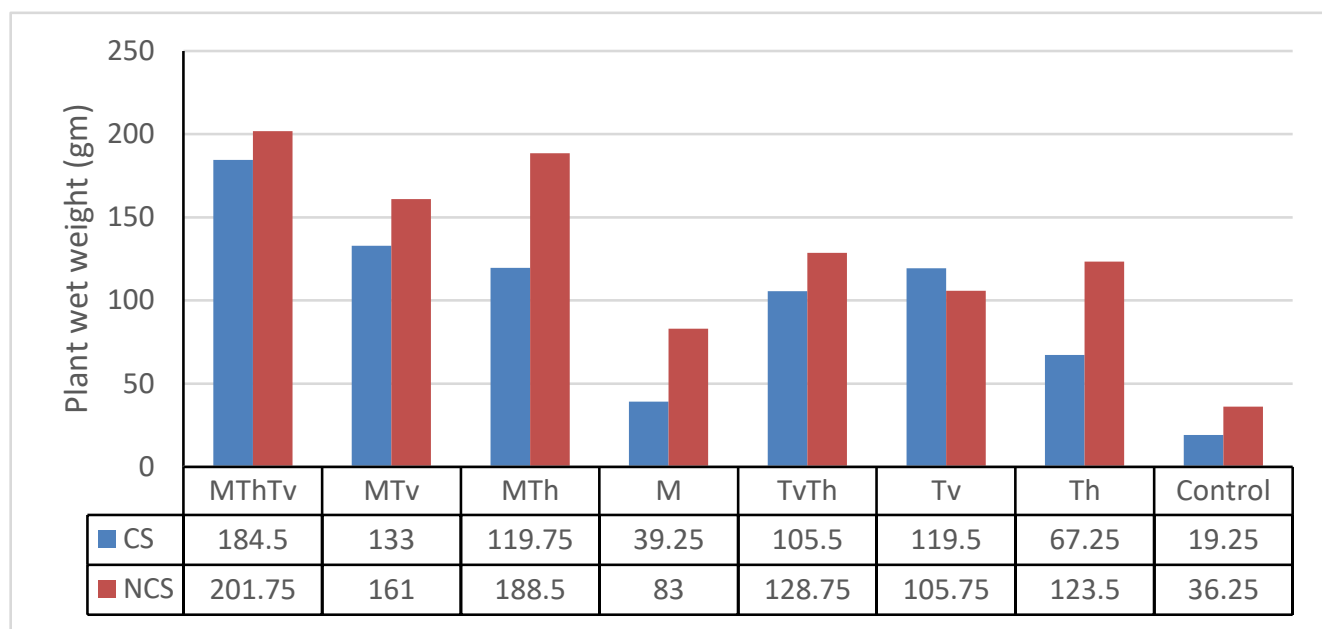

Fig. (7): The effect of experimental treatments on radish wet weight in both $M$. javanica contaminated and non-contaminated soils. Each mean represents 4 replicates. LSD 0.05 of interaction $=15.31$, LSD 0.05 of Soil $=21.66$.

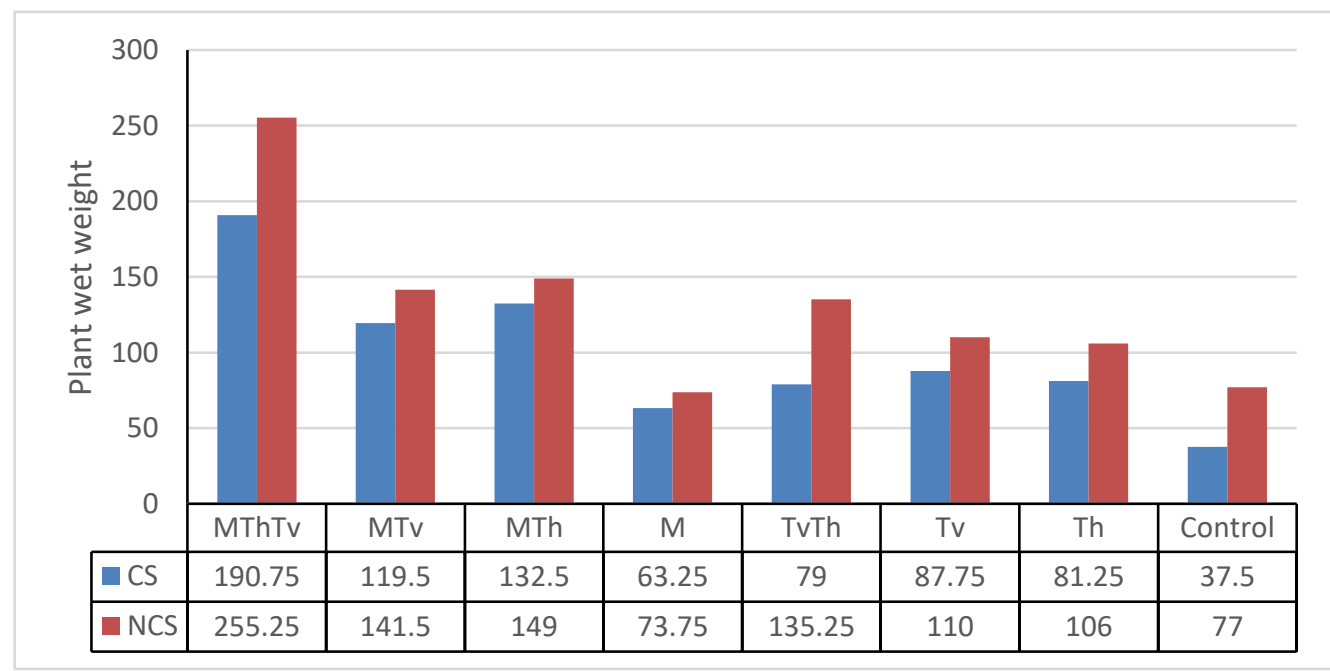

Fig. (8): The effect of experimental treatments on chard wet weight in both $M$. javanica contaminated and non-contaminated soils. Each mean represents 4 replicates. LSD 0.05 of interaction $=25.04$, LSD 0.05 of Soil $=8.85$.

The results revealed a notable increase in plant height and wet weight in all biocontrol agent included treatments of both CS and NCS treatments comparing with control treatments separately. Actually, there are several proposed mechanisms may interprets these results like (i) the ability of Trichoderma spp. to increases supplement of major and minor nutrients to the host plant, (ii) the secretion of growth hormones (like
Indole Acetic Acid) that reflecting positively on plant growth and production, and (iii) the fungus can reduces the average eggs hatching, the total nematodes population and promoting the biochemical defences of the plants, which indeed protects the plant and elevates its selfresistance level (Baker, 1989; Okoth et al., 2011). The differences among CS and NCS treatments results may be due to the nature of the nematode infection that represented by 
sever feeding on invaded roots and formation of root knots, which affect the ability of root system to supply plant with water and nutrient needs (Sikora \& Kiewnick, 2006).

\section{Conclusion}

The radish and chard plants are severely infected by root-knot nematodes $M$. javanica causing highly economic losses to both of them. The use of the biological control by $T$. harzianum and $T$. viride in accompanying with the organic fertilizers will redacting infection severity and significantly increasing the plant vegetative growth.

\section{Acknowledgement}

We would like to thank the staff of laboratory of Molecular Genetics, College of Agriculture, University of Basrah for their valuable help and cooperation in molecular part of this research.

\section{References}

Abad, P.; Favery, B.; Rosso, M.N. \& Castagnon Sereno, P. (2003). Root-knot nematode parasitism and host response: molecular basis of sophisticated interaction. Mol. Plant Pathol., 4: 217-224.

Aydinli, G. \& Mennan, S. (2016). Identification of root-knot nematodes (Meloidogyne spp.) from greenhouses in the Middle Black Sea Region of Turkey. Turk. J. Zool., 40(5), 675-685. https://doi.org/10.3906/zoo-1508-19.

Agrios, G.N. (2005). Plant Pathology. Elsevier Academic Press Publication: 952pp.

Al-Waily, D.S.A. (2004). A study of tomato seedling damping-off disease and their integrated controlin the fields of Zubair and Safwan in Basrah. Ph. D. Thesis. Univ. Basrah: 96pp.
Baker, R. (1989). Improved Trichoderma spp. for promoting crop productivity. Trends Biotechnol., 7: 3438.

Bird, D.M. \& Kaloshian, I. (2003). Are roots special Nematodes have their say. Physiol. Mol. Plant Pathol., 62: 115-123.

Bridge, J. \& Page, S.L.J. (1980). Estimation of root-knot nematode infestation levels on roots using a rating chart. Trop. Pest Manage., 26: 296-298.

Cook, R.J. (2000). Advances in plant health management in the twentieth century. Annu. Rev. Phytopathol., 38: 95-116.

Davis, E.L.; Hussey, R.S. \& Baum, T.J. (2004). Getting to the roots of parasitism by nematodes. Trends Parasitol., 20: 134141.

Hirschmann, H. (1985). The classification of the family Meloidogynidae: 35-45. In Sasser, J.N. \& Carter, C.C. (Eds.). An Advanced Treatise on Meloidogyne, Vol. 1. Dept. Plant Pathology, US Agency for International Development, Raleigh, N.C.: $422 \mathrm{pp}$.

Luc, M.; Sikora, R.A. \& Bridge, A. (1990). Plant Parasitic Nematodes in Subtropical and Tropical Agriculture. CABI.: 241pp.

Matloob, A.N.; Sultan, I. \& Abdool, K.S. (1989). Vegetable production. $2^{\text {nd }}$ Part. Book house of printing and publishing. Univ. Mosul Press. 337pp. (In Arabic).

McClure, M.A.; Kruk, T.H. \& Misaghi, I. (1972). A method for obtaining quantities of clean Meloidogyne eggs. Nematologiea., 5: 230 .

Mukerji, K.G. \& Garg, K.L. (1987). Trichoderma as biocontrol agent. Biocontrol. Plant Dis., 1: 71-82 . 
Okoth, S.A.; Otadoh, J.A. \& Ochanda, J.O. (2011). Improved seedling emergence and growth of maize and beans by Trichoderma harziunum. Trop. Subtrop. Agroecosyst., 13: 65-71.

Papavizas, G.C.; Lewis, J.A., \& Abd-Elmoity, T.H. (1982). Evolution of new biotypes of Trichoderma harzianum for tolerance to benomyl and enhanced Biocontrol capabilities. Phytopathology, 72: 126-132.

Perry, R.N.; Moens, M. \& Starr, J. (2010). Root-Knot Nematodes. CABI: 531pp.

Sikora, R.A. \& Kiewnick, S. (2006). Biological control of the root-knot nematode Meloidogyne incognita by
Paecilomyces lilacinus strain 251. Biol. Control, 38: 179-187.

Singh, N. \& Siddiqui, Z.A. (2012). Inoculation of Tomato with Ralistonia solanacearium, Xanthomonas campestris, and Meloidogyne javanica. Int. J. Veg. Sci., 18: 78-86.

Zijlstra C.; Donkers-Venne, D.THM, \& Fargette, M. (2000). Identification of Meloidogyne incognita, M. javanica, and $M$. arenaria using sequence characterised amplified region (SCAR) based PCR assays. Nematology, 2: 847-853. 